\title{
Developments of the Efficient Water-splitting Electrodes under the Visible Light Irradiation
}

\author{
Yoshinori Murakami, Ponchio Chatchai, and Yoshio Nosaka
}

\begin{abstract}
Department of Chemistry, Nagaoka University of Technology (1603-1 Kamitomioka, Nagaoka, Niigata 940-2118, Japan)
\end{abstract}

Received September 22, 2008 ; Accepted November 4, 2008

\begin{abstract}
Our recent works on the photoelectrochemistry and fabrication of the water-splitting photocatalyst for solar energy conversion were reported. The S-dope midgap states were determined by monitoring the effect of the photocurrent on the addition of several reductants. The midgap states for the S-doped anatase $\mathrm{TiO}_{2}$ has higher redox potentials than those of the $\mathrm{Br} \cdot / \mathrm{Br}^{-}$and possesses the additional multiple oxidation states of $\mathrm{S}$ cations. The laser ablation of the $\mathrm{BiVO}_{4}$ and $\mathrm{BiZn}_{2} \mathrm{VO}_{6}$ photocatalytic particulates in water reduced these sizes and it was found that the thin film electrode prepared by calcining the laser-ablated $\mathrm{BiVO}_{4}$ and $\mathrm{BiZn}_{2} \mathrm{VO}_{6}$ suspensions showed higher photocurrent efficiencies compared with the electrodes prepared without laser-ablation. The composite electrode $\mathrm{FTO} / \mathrm{SnO}_{2} / \mathrm{BiVO}_{4}$ and $\mathrm{FTO} / \mathrm{WO}_{3} / \mathrm{BiVO}_{4}$ were prepared by a solution method and the photocurrent efficiencies for these electrodes were found to be increased due to the mediator effect of $\mathrm{SnO}_{2}$ and $\mathrm{WO}_{3}$, which helps the electrons in the conduction band of $\mathrm{BiVO}_{4}$ to transfer to the FTO. The new photocatalytic particulates that are active for oxygen evolution under the visible light irradiation was searched and the $\mathrm{BiCu}_{2} \mathrm{PO}_{6}$ was found to be active with the addition of sacrifice under the visible light irradiations.
\end{abstract}

Key Words : Photoelectrode, Water-splitting, Photocatalyst, Visible Light

\section{Introduction}

Since the pioneering work of Fujishima and Honda, ${ }^{1)}$ the water splitting reactions at semiconductor surfaces and the production of clean fuel $\mathrm{H}_{2}$ from water under the solar light irradiations has been a dream for many scientists. Until 1980s, research on the water-splitting photocatalysts was largely devoted to $\mathrm{TiO}_{2}$ and $\mathrm{SrTiO}_{3}$. But after the discovery of $\mathrm{K}_{4} \mathrm{Nb}_{6} \mathrm{O}_{17}$ water-splitting photocatalysis, ${ }^{2)}$ numerous kinds of photocatalytic materials that can achieve efficient and stable water splitting such as $\mathrm{ZrO}_{2}$, ${ }^{3)} \mathrm{Ta}_{2} \mathrm{O}_{5}{ }^{4)}$ and $\mathrm{GaN}^{5}$ have been reported. Now the $\mathrm{NiO} / \mathrm{NaTaO}_{3}: \mathrm{La}$ photocatalyst shows as high as $56 \%$ quantum yield at 270 -nm light irradiation. $\left.{ }^{6}\right)$ Recently visible-light driven water-splitting photocatalysts attracted much attention because of the practical and efficient utilization of solar light and various types of photocatalysts that can dissociate water under visible light irradiations were synthesized so far. Thus the oxygen and hydrogen evolution for these new types of water-splitting photocatalysts have been intensively investigated, but fewer works have been carried out on the photoelectrochemical properties for the photocatalytic materials other than the $\mathrm{TiO}_{2}$ photocatalysts. Since the photoelectrochemical investigations for the photocatalytic materials give us new insights for finding out a new photocatalytic system that can function even under the visible light irradiation, the research on the photoelectrochemistry for these visible-light driven water-splitting photocatalysts are also very important.

In this article, we introduced our recent results of the photoelectrochemistry for the visible-light response photocatalysts and also show new manufacturing processes to enhance the photocurrent efficiencies for these photocatalytic electrodes.

\section{Photocurrent Properties of the Sulfur-Doped $\mathrm{TiO}_{2}$ Film Electrodes}

Recent studies revealed that the doping of a titanium dioxide $\left(\mathrm{TiO}_{2}\right)$ with other elements such as nitrogen, ${ }^{7)}$ sulfur, ${ }^{8,9)}$ carbon $^{10)}$ extended the photoactive wavelength regions for decomposing organic compounds ${ }^{7-9)}$ as well as the water oxidation. ${ }^{10)}$ Kato et al. also reported that $\mathrm{TiO}_{2}$ co-doped with antimony and chromium evolves oxygen from aqueous silver nitrate solution under visible light irradiations. ${ }^{11)}$ The abilities of the water oxidation at the midgap states for such doped $\mathrm{TiO}_{2}$ photocatalysts are important for the developments and understanding of the visible-light responsive water splitting photocatalysts. Nakato and co-workers investigated the photocurrent characteristics of $\mathrm{N}$-doped ${ }^{12)}$ and $\mathrm{C}$-doped ${ }^{13)} \mathrm{TiO}_{2}$ under the UV and visible irradiations and proposed the new mechanism of water oxidation via a nucleophilic attack of a water molecule on a surface trapped hole.

We have also investigated the photocurrent properties of S-doped $\mathrm{TiO}_{2}$ under the visible light irradiation. For the S-doped $\mathrm{TiO}_{2}$ photocatalysts, both of the S-doped anatase and the S-doped rutile $\mathrm{TiO}_{2}$ were prepared for comparison. For these S-doped $\mathrm{TiO}_{2}$ the effect of hydroquinone $(\mathrm{HQ}), \mathrm{I}^{-}, \mathrm{SCN}^{-}$, or $\mathrm{Br}^{-}$added as a reductant on the dependence of the incident photon to current efficiency (IPCE) was investigated as a function of the irradiation wavelength for each S-doped $\mathrm{TiO}_{2}$ film. The results were shown in Fig. 1.

As shown in Fig. 1, the IPCE for the S-doped anatase 
$\mathrm{TiO}_{2}$ films increased only for $\mathrm{KI}$ and hydroquinone, but the IPCE for the S-doped rutile $\mathrm{TiO}_{2}$ increased for all of the reductants. The photocurrent enhancements by the addition of hydroquinone were explained by the chargetransfer complex between the hydroquinone and the $\mathrm{TiO}_{2}$, but the different oxidation behaviors between the S-doped anatase and the S-doped rutile $\mathrm{TiO}_{2}$ toward the added reductants could not be explained by the band gap narrowing and the oxygen vacancy levels below the conduction band as pointed out by Nakamura et al. ${ }^{12)}$ Thus the different position of the midgap states between the anatase and rutile for S-doped $\mathrm{TiO}_{2}$ was suggested. To obtain the redox potential of the doped states for the S-doped anatase and rutile $\mathrm{TiO}_{2}$, Tauc plots of the $(\alpha h v)^{1 / 2}$ vs photon energy were performed and the midgap states for the S-doped anatase $\mathrm{TiO}_{2}$ was 1.4-2.3 $\mathrm{eV}$ but 2,4 eV for the $\mathrm{S}$-doped rutile $\mathrm{TiO}_{2}$. The schematic figure of the midgap states of the S-doped anatase and rutile $\mathrm{TiO}_{2}$ electrodes are shown in Fig. 2.

Thus the impurity states of S-doped anatase have broader distributions, and the lowest mid gap of these doped states lies between the redox potential of $\mathrm{I} \cdot / \mathrm{I}^{-}$ and $\mathrm{SCN} \cdot / \mathrm{SCN}^{-}$. On the other hand, the doped states of the S-doped rutile $\mathrm{TiO}_{2}$ had higher redox potentials than those of the $\mathrm{Br} \cdot / \mathrm{Br}$ - These results suggested that the S-doped anatase $\mathrm{TiO}_{2}$ possesses the additional multiple oxidation states of $\mathrm{S}$ cations as indicated by Ohno et al.9) Thus the electrochemical analysis of the photocatalysis will give us more detailed information of the band positions as well as the photocatalytic activities for each midgap states.
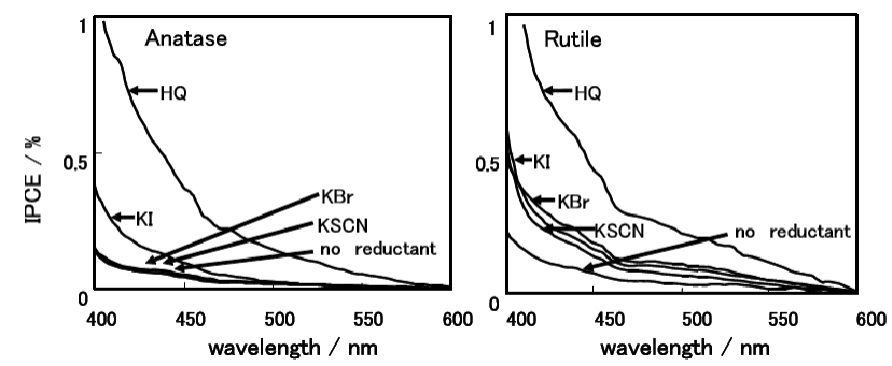

Fig. 1 The IPCE versus wavelength for the S-doped anatase (left) and rutile (right) electrodes. ${ }^{14)}$

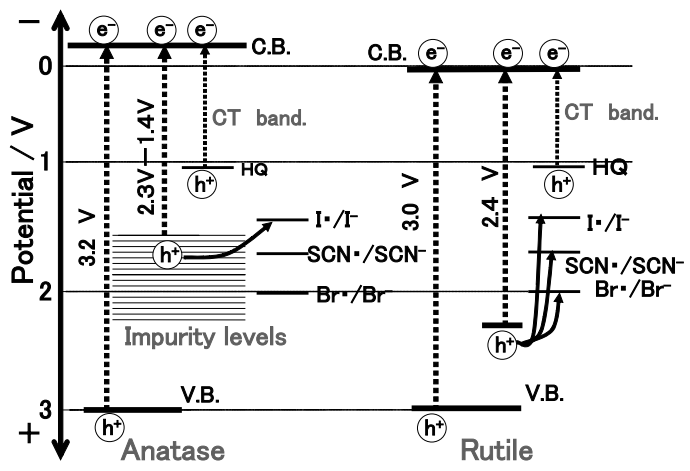

Fig. 2 Schematic figure of the electronic states of the Sdoped anatase and rutile $\mathrm{TiO}_{2}$ electrodes. ${ }^{14)}$

\section{Laser Ablation of the Photocatalytic Powders in Water and Application to the Fabrication of the Thin Film Electrode}

It was demonstrated in the previous section that the electrochemical analysis for the visible-light driven photocatalysts was useful for investigating not only the position of the conduction band, valence band and the midgap states and also the mechanism of the oxidation and reduction reactions on the photocatalytic surfaces. Although a considerable number of high efficient visiblelight responsive photocatalysts have been reported so far, fewer reports have been worked on the electrochemical anaylsis for such a visible-light responsive photocatalyst. This is partly because most of the photocatalysts were prepared in the form of particulates and it is difficult to prepare the thin-film electrode from the photocatalytic particulates.

Recently several authors have reported the size reduction of gold and silver particles by the pulsed laser ablation in water. ${ }^{15)}$ Sugiyama et al. also reported the size reduction of the photocatalytic $\mathrm{TiO}_{2}$ particulates up to 10 $\mathrm{nm}$ by the $308 \mathrm{~nm}$ pulsed laser ablation. ${ }^{16)}$ However no further experiments on the size reduction of the other water-splitting photocatalytic particulates by the pulsed laser ablation in water have been reported. By reducing the size of the individual particles by the pulsed laser ablation of the particles in water, the contacts between the particles and the thin film electrode will be enhanced and thus it is expected that the photocurrent for the thin film electrode prepared will also increase.

Figure 3 shows the SEM images of the $\mathrm{BiVO}_{4}$ powders as received and those of the $\mathrm{BiVO}_{4}$ powders after the laser ablation with a $308 \mathrm{~nm} \mathrm{XeCl}$ laser for $2 \mathrm{~h}$. The typical pulse energy of the $308 \mathrm{~nm} \mathrm{XeCl}$ laser was around $100 \mathrm{~mJ} /$ pulse and the laser beam was focused on the center of cubette with a lens $(\mathrm{f}=150 \mathrm{~mm})$. The photocatalytic $\mathrm{BiVO}_{4}$ powders, which were irradiated by the $\mathrm{XeCl}$ laser light, were suspended in water by stirring the mixture. As shown in Fig. 3, most of the $\mathrm{BiVO}_{4}$ particles were reduced to $<5 \mu \mathrm{m}$ after the laser ablation for $2 \mathrm{~h}$. To confirm further the size reduction of the $\mathrm{BiVO}_{4}$ particulates by the laser ablation processes, the laser diffraction and scattering analyzer was used to observe the size distribution of the non-laser and laser-ablated suspensions of the $\mathrm{BiVO}_{4}$ particulates. As shown in Fig. 4, before the laser ablation, the particle diameter of the

(a)

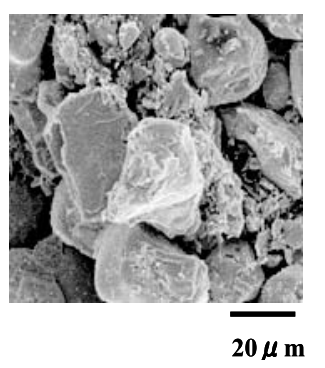

(b)

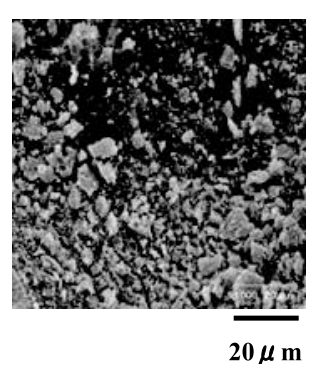

Fig. 3 SEM images of the $\mathrm{BiVO}_{4}$ particles for (a) as received and (b) $2 \mathrm{~h}$ irradiation of $308 \mathrm{~nm}^{22}$ 
$\mathrm{BiVO}_{4}$ powders ranged from 5 to $100 \mu \mathrm{m}$, while after the laser ablation of the $\mathrm{BiVO}_{4}$ particles in water for $2 \mathrm{~h}$, the particle diameter was ranged below $5 \mu \mathrm{m}$, similar to the SEM observations.

After the fabrication of the thin film electrode by calcining the laser-ablated $\mathrm{BiVO}_{4}$ suspensions at $500{ }^{\circ} \mathrm{C}$ in air for $30 \mathrm{~min}$, the photocurrent measurements were performed. For comparison, the photocurrent of the particulate $\mathrm{BiVO}_{4}$ thin film electrode based on the technique reported by Liu et al. ${ }^{17)}$ was also measured. The results are shown in Fig. 5. As shown in Fig. 5, the thin film electrode of the laser-ablated $\mathrm{BiVO}_{4}$ particulates showed higher photocurrent efficiency compared with that of the particulate $\mathrm{BiVO}_{4}$.

The effects of the laser ablation on the $\mathrm{BiVO}_{4}$ crystal structures were also investigated, but although the XRD patterns for the laser-ablated $\mathrm{BiVO}_{4}$ particles showed the amorphous components at lower diffraction angles, the amorphous components disappeared when the laserablated $\mathrm{BiVO}_{4}$ particulates were calcined at $450{ }^{\circ} \mathrm{C}$ for 30 min. Thus the laser ablation processes of the $\mathrm{BiVO}_{4}$ photocatalytic particles did not cause the phase transition of the $\mathrm{BiVO}_{4}$ crystal structures.

To investigate further the reason that the laser-ablat-

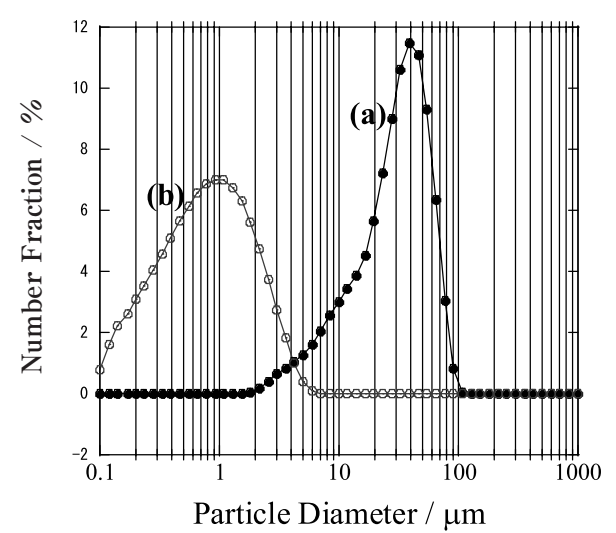

Fig. 4 Diameter distributions of the $\mathrm{BiVO}_{4}$ particles with (a) as received and (b) after $2 \mathrm{~h}$ of the $308 \mathrm{~nm}$ laser irradiation. ${ }^{22)}$

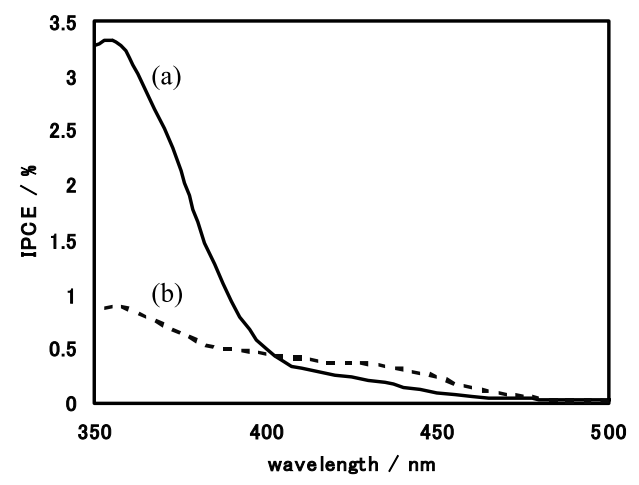

Fig. 5 Photocurrent action spectra of the $\mathrm{BiVO}_{4}$ particulate thin film electrodes prepared (a) from particulates with the $2 \mathrm{~h} \mathrm{XeCl-laser} \mathrm{ablation} \mathrm{and} \mathrm{(b)} \mathrm{by} \mathrm{the}$ sol-gel method. ${ }^{22)}$ ed particulate thin electrode shows the increased photocurrent, laser ablation and fabrication of thin film electrode for the $\mathrm{BiZn}_{2} \mathrm{VO}_{6}$ photocatalytic powders were performed. The photocatalytic $\mathrm{BiZn}_{2} \mathrm{VO}_{6}$ powders were prepared according to the techniques reported in the previous literature. ${ }^{18)}$ The size distributions of the $\mathrm{BiZn}_{2} \mathrm{VO}_{6}$ powders for without laser ablation, $1 \mathrm{~h}$ laser ablation at $355 \mathrm{~nm}$ and $1 \mathrm{~h}$ laser ablation at $532 \mathrm{~nm}$ were given in Fig. 6. Because the band edge of $\mathrm{BiZn}_{2} \mathrm{VO}_{6}$ was around $550 \mathrm{~nm}$, the difference of the size reduction by the laser ablation processes between the 532-nm laser and 355-nm laser is explained by the difference of the absorbance of the photocatalytic materials. The XRD analysis after the laser ablation of the $\mathrm{BiZn}_{2} \mathrm{VO}_{6}$ powders were performed and confirmed that the laser ablation did not induce the phase transitions for the $\mathrm{BiZn}_{2} \mathrm{VO}_{6}$ crystal structures.

Figure 6 shows the results of the photocurrent action spectra of the $\mathrm{BiZn}_{2} \mathrm{VO}_{6}$ particulate thin electrode with $355 \mathrm{~nm}$ and $532 \mathrm{~nm}$ laser irradiations. Although the size reduction of the $\mathrm{BiZn}_{2} \mathrm{VO}_{6}$ photocatalytic powders was negligibly small, the photocurrent enhancements by the 532-nm laser ablation are as large as those by the 355-nm laser ablation. Recently Nakato et al. suggested that the surface defects play the key roles of the oxygen evolution by the nucleophilic attack of $\mathrm{H}_{2} \mathrm{O}$ on the steps and the corners of $\mathrm{TiO}_{2}$ surfaces. ${ }^{19,20)} \mathrm{We}$ have previously demonstrated that the vaporization of Mo atoms from Mo nanoparticles occurred just after the laser irradiation processes. ${ }^{21)}$ That is, even if the phase transition could not occur in these experimental conditions, the defect formation on the surface could be caused by the laser ablation processes.

Thus the photocurrent enhancements due to not only the size reduction but also the formation of the surface defect caused by the laser ablations of $\mathrm{BiVO}_{4}$ and $\mathrm{BiZn}_{2} \mathrm{VO}_{6}$ photocatalytic particulates in water were suggested. ${ }^{22)}$ This technique will open the new way to fabricate the thin film electrode of the photocatalytic materials that are in the powder forms and also have difficulty to prepare thin film electrode because of the large particle sizes.
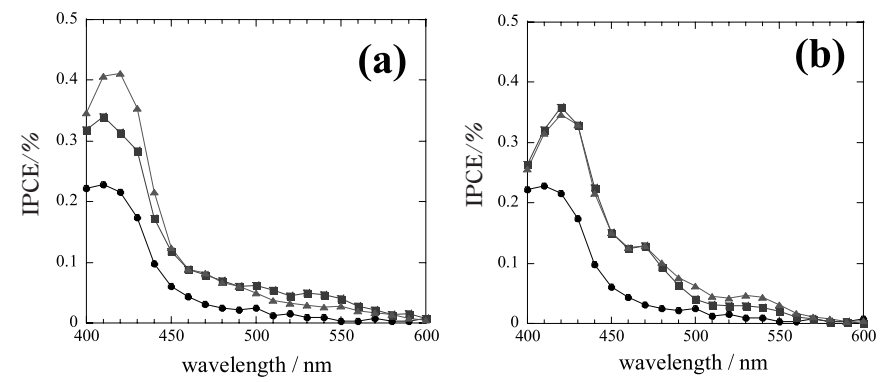

Fig. 6 Photocurrent action spectra of the $\mathrm{BiZn}_{2} \mathrm{VO}_{6}$ particulate thin electrode with (a) $355 \mathrm{~nm}$ laser ablation and with (b) $532 \mathrm{~nm}$ laser ablation. are no laser irradiation, and $\boldsymbol{\square}$ are the 30 min laser irradiation and $\boldsymbol{\Delta}$ are the 60 min laser irradiation. ${ }^{22)}$ 


\section{Fabrication of the Visible-Light Driven Composite Photoelectrode for Water Oxidation}

Recently composite electrodes of the metal and the photocatalytic thin film is attracting extensive interest for the separate generation of hydrogen and oxygen ${ }^{23,24}$ as well as the enhanced charge separation and the higher IPCE values. ${ }^{25,26)}$ On the other hand, little works were carried out for the composite films of the visible-light driven photocatalysts. In this article, we will introduce our recent results on the increase of the photocurrent efficiencies using the heterojunction of the $\mathrm{SnO}_{2} / \mathrm{BiVO}_{4}{ }^{27}$ ) and of the $\mathrm{WO}_{3} / \mathrm{BiVO}_{4}$ electrodes. ${ }^{28)}$

$\mathrm{BiVO}_{4}$ and $\mathrm{SnO}_{2}$ sols are prepared following the previous works of Sayama et al. ${ }^{29)}$ and Cao et al., ${ }^{30)}$ respectively. The precursor solutions for $\mathrm{SnO}_{2}$ and $\mathrm{BiVO}_{4}$ were coated by using a spin coater on the FTO substrate, respectively. After coating, the FTO glass was dried and calcined at $450{ }^{\circ} \mathrm{C}$ for $1 \mathrm{~h}$. Not only the FTO/ $\mathrm{SnO}_{2} / \mathrm{BiVO}_{4}$ electrode, but also the $\mathrm{FTO} / \mathrm{BiVO}_{4} / \mathrm{SnO}_{2}$ electrode was prepared for comparison. Figure 7 shows the cross-sectional SEM images of the FTO/ $\mathrm{SnO}_{2} / \mathrm{BiVO}_{4}$ electrode (right, Fig. 7(A)) and FTO electrode (left, Fig. 7(B)).

Although FTO (F-doped $\mathrm{SnO}_{2}$ ) layer of $1.1 \mu \mathrm{m}$ is observed on the glass, the $\mathrm{FTO} / \mathrm{SnO}_{2} / \mathrm{BiVO}_{4}$ electrode have additional bilayer structures with thickness of $1 \mu \mathrm{m}$ for both layers of $\mathrm{BiVO}_{4}$ and $\mathrm{SnO}_{2}$ on the FTO substrate. The XRD analysis for the FTO/ $\mathrm{SnO}_{2} / \mathrm{BiVO}_{4}$ electrode confirmed the formation of $\mathrm{BiVO}_{4}$ and $\mathrm{SnO}_{2}$ layer on the FTO substrate.
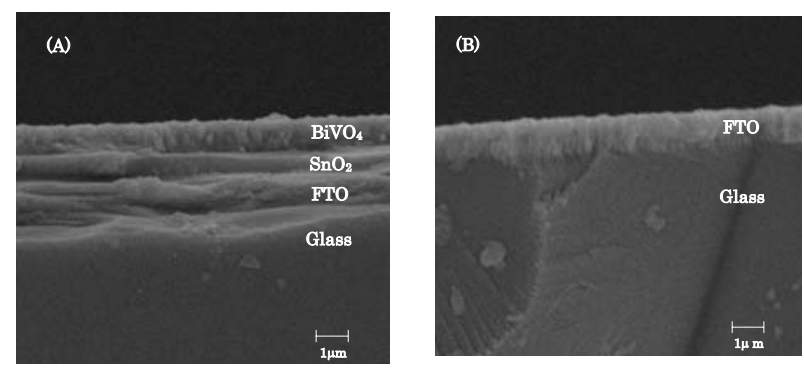

Fig. 7 SEM Images of the cross section for the asdeposited coating of (A) FTO/ $\mathrm{SnO}_{2} / \mathrm{BiVO}_{4}$ electrode and (B) FTO electrode. ${ }^{27)}$

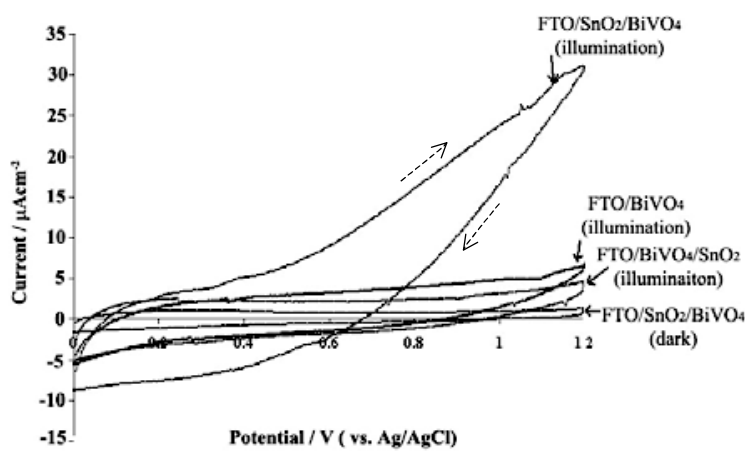

Fig. 8 Cyclic voltammograms of $\mathrm{FTO} / \mathrm{SnO}_{2} / \mathrm{BiVO}_{4}$, FTO $/ \mathrm{BiVO}_{4} / \mathrm{SnO}_{2}$, and $\mathrm{FTO} / \mathrm{BiVO}_{4}$ in the presence and absence of light illuminations $(>420 \mathrm{~nm})$. Electrolyte solution, $\mathrm{N}_{2}$-bubbled $0.5 \mathrm{M} \mathrm{Na}_{2} \mathrm{SO}_{4}{ }^{27)}$
Figure 8 is the cyclic voltammograms of $\mathrm{FTO} / \mathrm{SnO}_{2} / \mathrm{BiVO}_{4}, \mathrm{FTO} / \mathrm{BiVO}_{4} / \mathrm{SnO}_{2}$ and $\mathrm{FTO} / \mathrm{BiVO}_{4}$ electrode in the presence and absence of light illuminations $(>420 \mathrm{~nm})$. Significant enhancements in the anodic photocurrent was observed at the potential more positive than $+0.4 \mathrm{~V}$ (vs. $\mathrm{Ag} / \mathrm{AgCl}$ ) for the $\mathrm{FTO} / \mathrm{SnO}_{2} / \mathrm{BiVO}_{4}$ electrode compared to those of $\mathrm{FTO} / \mathrm{BiVO}_{4}$. The negative shift of the onset potential of $\mathrm{FTO} / \mathrm{SnO}_{2} / \mathrm{BiVO}_{4}$ corresponds to the increased photoelectrochemical activity. The photocurrent of the $\mathrm{FTO} / \mathrm{BiVO}_{4} / \mathrm{SnO}_{2}$ electrode, however, decreased compared with the $\mathrm{FTO} / \mathrm{BiVO}_{4}$ electrode. Figure 9 shows the IPCE values for these electrodes as a function of the irradiation wavelength. It was found that the action spectra resembles to the absorption spectra of $\mathrm{BiVO}_{4}$ and the photocurrent efficiency of the $\mathrm{FTO} / \mathrm{SnO}_{2} / \mathrm{BiVO}_{4}$ is higher than that of the FTO/ $/ \mathrm{BiVO}_{4}$ in both regions of UV and visible light. The photocurrent efficiency of the $\mathrm{FTO} / \mathrm{BiVO}_{4} / \mathrm{SnO}_{2}$ electrode was lower than the $\mathrm{FTO} / \mathrm{BiVO}_{4}$ in both regions of $\mathrm{UV}$ and visible light

A plausible mechanism for such photocurrent properties is schematically shown in Fig. 10(A). The photo induced electrons in the conduction band of $\mathrm{BiVO}_{4}$ move to the conduction band of the $\mathrm{SnO}_{2}$ interface and a bar-

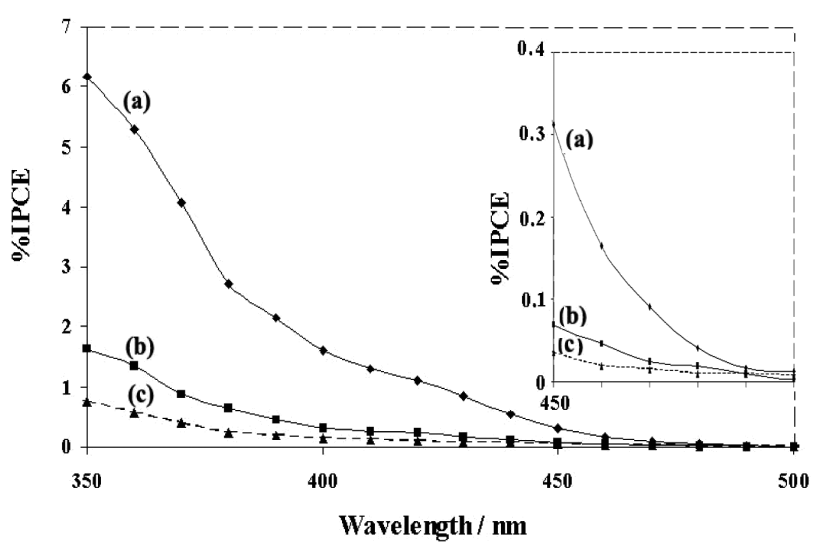

Fig. 9 The IPCE action spectra of (a) FTO/ $\mathrm{SnO}_{2} / \mathrm{BiVO}_{4}$, (b) FTO/BiVO bubbled $0.5 \mathrm{M} \mathrm{Na}_{2} \mathrm{SO}_{4}$ under an applied potential of $1.0 \mathrm{~V}$ vs $\mathrm{Ag} / \mathrm{AgCl}$. The insert shows the expansion of ordinate. ${ }^{27)}$

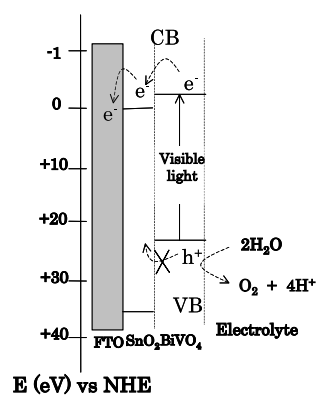

(A)

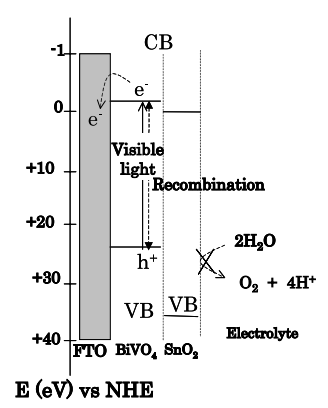

(B)
Fig. 10 Schematic energy diagram of the charge transfer processes in the bilayer electrodes at $\mathrm{pH} 0$. (A) FTO $/ \mathrm{SnO}_{2} / \mathrm{BiVO}_{4}$ (B) FTO $/ \mathrm{BiVO}_{4} / \mathrm{SnO}_{2}{ }^{27}$ ) 


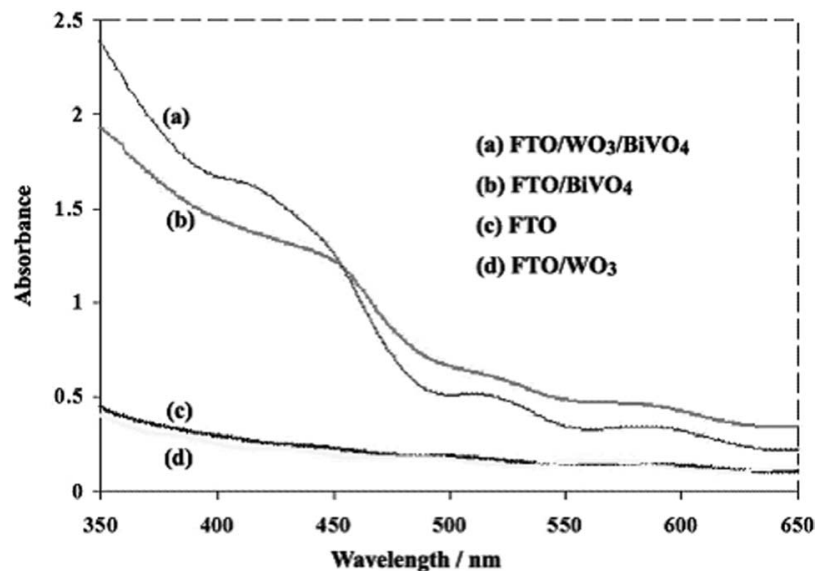

Fig. 11 Absorption spectra of (a) $\mathrm{FTO} / \mathrm{WO}_{3} / \mathrm{BiVO}_{4}$, (b) FTO/BiVO

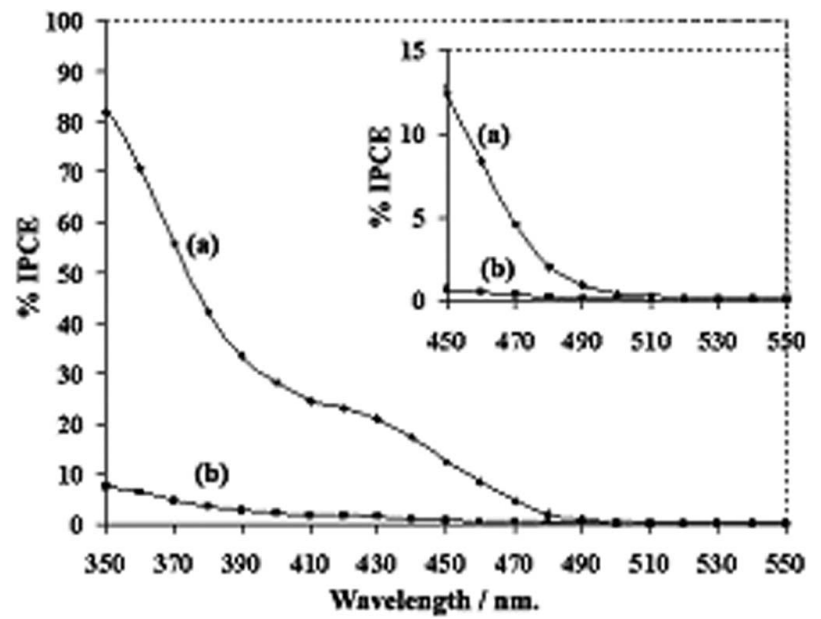

Fig. 12 The \% IPCE action spectra of (a) FTO $/ \mathrm{WO}_{3} / \mathrm{BiVO}_{4}$ and (b) FTO/BiVO 4 electrodes in $\mathrm{N}_{2}-$ bubled $0.5 \mathrm{M} \mathrm{Na}_{2} \mathrm{SO}_{4}$ aqueous solution under an applied potential of $1.0 \mathrm{~V}$ vs. $\mathrm{Ag} / \mathrm{AgCl}$. The inset shows the expansion of ordinate. ${ }^{28)}$

rierbetween the conduction bands of $\mathrm{BiVO}_{4}$ and $\mathrm{SnO}_{2}$ was low enough to suppress the recombination between the electron and holes in the $\mathrm{BiVO}_{4}$ photocatalysts.

On the other hand, as for the reverse coupled $\mathrm{FTO} / \mathrm{BiVO}_{4} / \mathrm{SnO}_{2}$ electrode, the electrons prefer to migrate into the FTO substrate and the remaining holes at the inner $\mathrm{BiVO}_{4}$ layer cannot be consumed because of the separation from water. Therefore the holes would be accumulated in the $\mathrm{BiVO}_{4}$ layer and recombined with the photo-induced conduction band electrons, resulting the decrease in the photocurrent (Fig. 10(B)).

Although we have succeeded in preparing the high efficient composite $\mathrm{FTO} / \mathrm{SnO}_{2} / \mathrm{BiVO}_{4}$ photocatalytic electrode under the visible irradiations, the IPCE values are not sufficient due to the fact that $\mathrm{SnO}_{2}$ semiconductor can not generate electron-hole pair under the visible irradiations. $\mathrm{WO}_{3}$ has attracted much attention because it shows the appropriate band gap energy level (c.a. $2.8 \mathrm{eV}$ ) and also the lower conduction band $\left(\mathrm{E}_{\mathrm{CB}}=+0.4 \mathrm{~V}\right.$ vs, $\mathrm{NHE}$ at $\mathrm{pH}$ 0). Thus we have attempted to prepare the

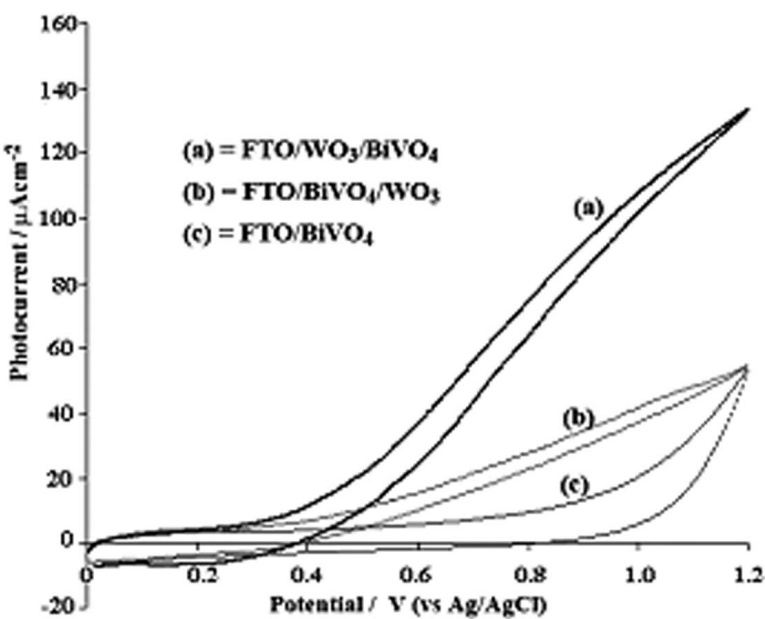

Fig. 13 Cyclic voltammograms with $\mathrm{FTO} / \mathrm{WO}_{3} / \mathrm{BiVO}_{4}$, FTO $/ \mathrm{BiVO}_{4} / \mathrm{WO}_{3}$ and $\mathrm{FTO} / \mathrm{BiVO}_{4}$ composite electrodes in $0.5 \mathrm{M} \mathrm{Na}_{2} \mathrm{SO}_{4}$ aqueous solution under the visible light illumination $\left(>420 \mathrm{~nm}\right.$ ). Scan rate was $50 \mathrm{mV} \mathrm{s}^{-1}$. Forward potential scan was from 0.0 to $1.2 \mathrm{~V}$ and the backward was from 1.2 to $0.0 \mathrm{~V}$ (vs. $\mathrm{Ag} / \mathrm{AgCl}$ ). Electrolyte solution was deaerated by $\mathrm{N}_{2}$ gas. ${ }^{28)}$

$\mathrm{FTO} / \mathrm{WO}_{3} / \mathrm{BiVO}_{4}$ composite electrode and measured the photocurrent efficiencies. $\mathrm{WO}_{3}$ film were prepared by a single coating of the $\mathrm{WO}_{3}$ solution by a spin coater and subsequent drying as was reported previously. ${ }^{31)}$ The coatings of $\mathrm{BiVO}_{4}$ was similar to the case of the FTO/ $\mathrm{SnO}_{2} / \mathrm{BiVO}_{4}$ electrode. The XPS and XRD analysis for the $\mathrm{FTO} / \mathrm{WO}_{3} / \mathrm{BiVO}_{4}$ composite electrode were also performed and it was confirmed that this electrode was consisted of the $\mathrm{WO}_{3}$ and $\mathrm{BiVO}_{4}$ layer. For comparison, not only the $\mathrm{FTO} / \mathrm{WO}_{3} / \mathrm{BiVO}_{4}$ electrode but also the FTO $/ \mathrm{BiVO}_{4} / \mathrm{WO}_{3}$ and $\mathrm{FTO} / \mathrm{BiVO}_{4}$ electrodes were prepared. Figure 11 shows the absorption spectra of (a) $\mathrm{FTO} / \mathrm{WO}_{3} / \mathrm{BiVO}_{4}$, (b) $\mathrm{FTO} / \mathrm{BiVO}_{4}$, (c) FTO and (d) FTO $/ \mathrm{WO}_{3}$ electrodes. As shown in Fig. 11, the $\mathrm{WO}_{3}$ layer was so thin that visible absorption of the $\mathrm{WO}_{3}$ was not obsered and it was confirmed that $\mathrm{WO}_{3}$ layer only act as the mediator of the electrom transfer from $\mathrm{BiVO}_{4}$ to FTO glass.

Figure 12 shows the cyclic voltammetry for the FTO $/ \mathrm{WO}_{3} / \mathrm{BiVO}_{4}, \mathrm{FTO} / \mathrm{BiVO}_{4} / \mathrm{WO}_{3}$ and $\mathrm{FTO} / \mathrm{BiVO}_{4}$ electrodes. As shown, the anodic photocurrent of the $\mathrm{FTO} / \mathrm{WO}_{3} / \mathrm{BiVO}_{4}$ was significantly enhanced as compared to those of the FTO/BiVO $4 / \mathrm{WO}_{3}$ and $\mathrm{FTO} / \mathrm{BiVO}_{4}$ electrodes at the potential more positive than $+0.4 \mathrm{~V}$ (vs. $\mathrm{Ag} / \mathrm{AgCl})$.

Figure 13 is the dependence of the IPCE on the wavelength in $\mathrm{Na}_{2} \mathrm{SO}_{4}$ solution with applied voltage of $1.0 \mathrm{~V}$ (vs. $\mathrm{Ag} / \mathrm{AgCl}$ ). The IPCE of the $\mathrm{FTO} / \mathrm{WO}_{3} / \mathrm{BiVO}_{4}$ was higher than the $\mathrm{FTO} / \mathrm{BiVO}_{4}$ electrode and the maximum IPCE was attained as high as $80 \%$ at $350 \mathrm{~nm}$. The IPCE action spectra also resemble to the absorption spectrum of $\mathrm{BiVO}_{4}$ and it was also found that the $\mathrm{WO}_{3}$ film was so thin that the visible absorption of $\mathrm{WO}_{3}$ was negligible in the form of the $\mathrm{FTO} / \mathrm{WO}_{3} / \mathrm{BiVO}_{4}$ electrode. Thus the role of $\mathrm{WO}_{3}$ layer is to mediate the electron transfer from $\mathrm{BiVO}_{4}$ to $\mathrm{FTO}$ and prevent the recombination of 


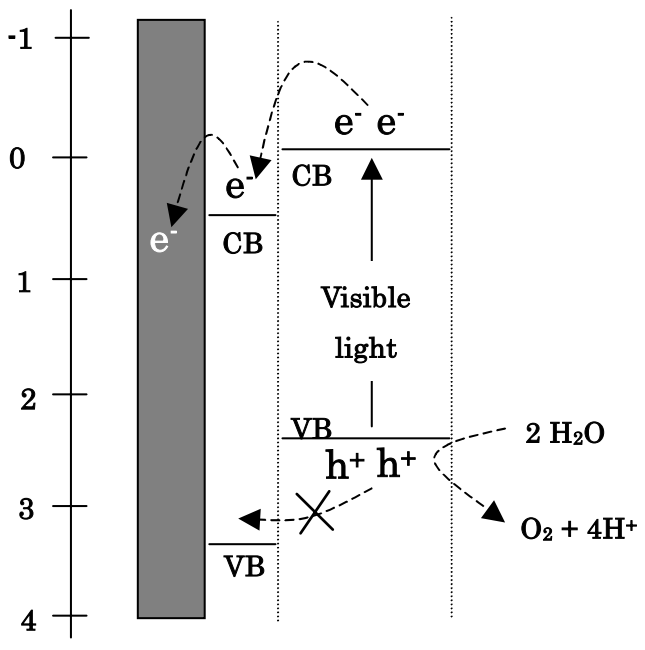

FTO $\mathrm{WO}_{3} \quad \mathrm{BiVO}_{4} \quad$ Electrolyte

Fig. 14 Energy diagram (at $\mathrm{pH}$ ) of the hetero junction of FTO $/ \mathrm{WO}_{3} / \mathrm{BiVO}_{4}$ electrode showing an effective chargetransfer process. ${ }^{28)}$

electron-hole pairs in $\mathrm{BiVO}_{4}$. The schematic figure for the role of $\mathrm{WO}_{3}$ in the $\mathrm{FTO} / \mathrm{WO}_{3} / \mathrm{BiVO}_{4}$ layer is shown in Fig. 14. This effect can decrease the applied potential for water oxidation and enhancing the photocurrent density.

Further work should be done for the search of the good mediator to enhance the photocurrent efficiency and the composite electrode will be the key to find out the high efficient electrodes to convert the solar-energy to the chemical energies in the near future.

\section{Photocatalytic Activity of the Phosphate Species: Search for the High-Efficient Photocatalyst that Evolve Oxygen}

As mentioned above, fabrication of the high efficient water-splitting electrodes are important. The most difficulty is the fabrication of the thin film electrode that evolves oxygen with high quantum efficiencies under the visible light irradiations. Now $\mathrm{BiVO}_{4}$ is most popular photocatalyst that evolve oxygen with the sacrifice such as $\mathrm{AgNO}_{3}$ under the visible light irradiations. Many (oxy)nitrides were found to be photocatalytic active for oxygen evolutions under the visible light irradiations. ${ }^{3)}$ Recently we have found that $\mathrm{BiCu}_{2} \mathrm{PO}_{6}$ is photocatalytic active for oxygen evolution under the visible irradiations. $\left.{ }^{32}\right)$ Figure 15 shows the amount of the total oxygen evolution for the photocatalyst $\mathrm{BiX}_{2} \mathrm{VO}_{6}(\mathrm{X}=\mathrm{Zn}$, $\mathrm{Cu}, \mathrm{Pb})$ and $\mathrm{BiY}_{2} \mathrm{PO}_{6}(\mathrm{Y}=\mathrm{Cu}, \mathrm{Pb})$ under the sacrifice. Although the photocatalytic activity of phosphate is lower than the vanadates, there is still some activity on oxygen evolution. Search for good photocatalysts is also necessary for finding out the good water splitting electrode under the solar irradiations and we expect that new types of high-efficient water-splitting photocatalysts will also help the fabrication of the high efficient watersplitting electrodes in future.

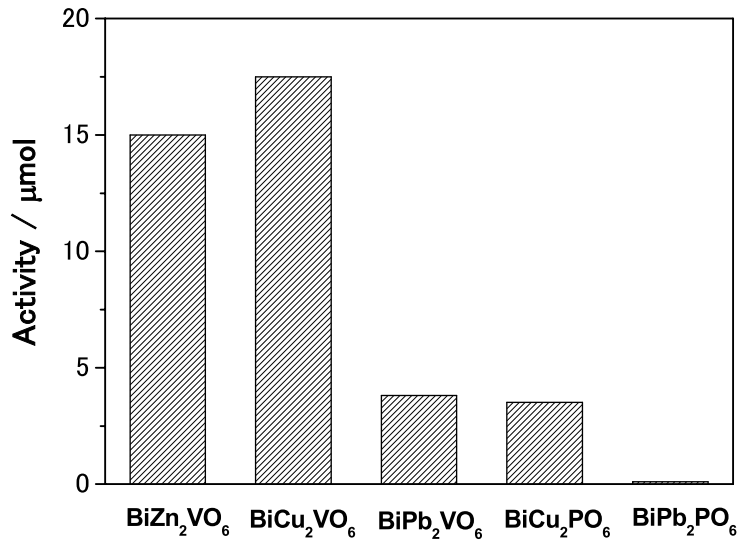

Fig. 15 Comparison of the amount of oxygen evolution for the photocatalyst $\mathrm{BiX}_{2} \mathrm{VO}_{6}(\mathrm{X}=\mathrm{Zn}, \mathrm{Cu}, \mathrm{Pb})$ and $\mathrm{BiY}_{2} \mathrm{PO}_{6}$ $(\mathrm{Y}=\mathrm{Cu}, \mathrm{Pb}$ ) under $40 \mathrm{ml}$ of $0.05 \mathrm{M} \mathrm{AgNO}$ solutions. The light source was $350 \mathrm{~W}$ Xe lamp combined with a cut-off glass filter $(\lambda>420 \mathrm{~nm}){ }^{32)}$ Irradiation time was $4 \mathrm{~h}$.

\section{Conclusion}

This article showed the important roles of the photoelectrochemistry in the developments of the visible-light driven photocatlysts. The positions of the midgap states in the S-doped anatase and rutile $\mathrm{TiO}_{2}$ were determined by monitoring the influence of the photocurrent efficiency on the addition of hydroquinone (HQ), $\mathrm{I}^{-}, \mathrm{SCN}^{-}$, or $\mathrm{Br}^{-}$ as a reductant. Application of the laser-ablation to the photocatalytic powders to fabricate the thin film electrode was introduced. The photocurrent enhancements were observed in both of the laser-ablated $\mathrm{BiVO}_{4}$ and $\mathrm{BiZn}_{2} \mathrm{VO}_{6}$ particulate electrodes. The composite electrode FTO $/ \mathrm{SnO}_{2} / \mathrm{BiVO}_{4}$ and $\mathrm{FTO} / \mathrm{WO}_{3} / \mathrm{BiVO}_{4}$ were fabricated and the photocurrents were increased in both electrodes. The roles of $\mathrm{SnO}_{2}$ and $\mathrm{WO}_{3}$ as mediators to transfer electrons from the conduction band of $\mathrm{BiVO}_{4}$ to FTO were suggested. Finally, the new types of water-splitting photocatalysts were investigated and the $\mathrm{BiCu}_{2} \mathrm{PO}_{6}$ was found to be active for oxygen evolution with the addition of sacrifice reagent under the visible light irradiation.

\section{Acknowledgement}

This work is partly supported by a Core Researcher for Evolution Science and Technology (CREST) from the Japan Science and Technology Agency (JST), Japan.

\section{References}

1) A. Fujishima and K. Honda, Nature, 238, 37 (1972).

2) A. Kudo, A. Tanaka, K. Domen, K. Maruya, K. Aika, and T. Onishi, J. Catal., 111, 67 (1988).

3) K. Sayama and H. Arakawa J. Photochem. Photobiol. A. 94, 67 (1996).

4) Y. Noda, B. Lee, K. Domen, and J. N. Kondo, Chem. Mater., 20, 5361 (2008).

5) Arai, N. Saito, H. Nishiyama, Y. Inoue, K. Domen, and K. Sato, Chem. Lett., 35, 796 (2006).

6) H. Kato, K. Asakura, and A. Kudo, J. Am. Chem. Soc., 125, 3082 (2003).

7) S. Sato, Chem. Phys. Lett., 123, 126 (1986). 
8) T. Umebayashi, T. Yamaki, H. Itoh, and K. Asai, Appl. Phys. Lett., 81, 454 (2002).

9) T. Ohno, T. Mitsui, and M. Matsumura, Chem. Lett., 32, 364 (2003).

10) S. U. M. Kahn, M. Al-Shahry, and W. B. Ingler, Jr. Science, 297, 2243 (2002).

11) H. Kato and A. Kudo, J. Phys. Chem. B., 106, 5029 (2002).

12) R. Nakamura, T. Tanaka, and Y. Nakato, J. Phys. Chem. B., 108, 10617 (2004).

13) L. Hamei, A. Imanishi, and Y. Nakato, J. Phys. Chem. C., 111, 8603 (2007).

14) Y. Murakami, B. Kasahara, and Y. Nosaka, Chem. Lett., 36, 330 (2007).

15) H. Kurita, A. Takami, and S. Koda, Appl. Phys. Lett., 72, 789 (1998).

16) M. Sugiyama, H. Okazaki, and S. Koda, Jpn. J. Appl. Phys. Part 2, 35, L781 (1996).

17) H. Liu, R. Nakamura, and Y. Nakato, J. Electrochem. Soc., 152, G856 (2005).

18) H. Liu, R. Nakamura, and Y. Nakato, Electrochem. SolidState. Lett., 9, G187 (2006).

19) R. Nakamura, T. Okamura, N. Ohashi, A. Imanishi, and Y. Nakato, J. Am. Chem. Soc., 127, 12975 (2005).

20) A. Tsujiko, K. Kajiyama, M. Kanaya, K. Murakoshi, and Y. Nakato, Bull. Chem. Soc. Jpn., 76, 1285 (2003).
21) Y. Murakami, T. Sugatani, and Y. Nosaka, J. Phys. Chem. A., 109, 8994 (2005).

22) Y. Murakami, M. Ikarashi, M. Hashizume, A. Y. Nosaka, and Y. Nosaka, Electrochem. Solid. State, Lett., 11, H42 (2008).

23) M. Kitano, K. Tsujimaru, and M. Anpo, Applied Catal. A., 314, 179 (2006).

24) S. Takabayashi, R. Nakamura, and Y. Nakato, J. Photochem. Photobiol. A., 166, 107 (2004).

25) E. M. El-Maghraby, Y. Nakamura, and S. Rengakuji, Catal. Comm., 9, 2357 (2008).

26) S. Higashimoto, M. Sakiyama, and M. Azuma, Thin. Solid. Film., 503, 201 (2006).

27) P. Chatchai, Y. Murakami, S. Kishioka, A. Y. Nosaka, and Y. Nosaka. Electrochem. Solid. State. Lett., 11, H160 (2008).

28) P. Chatchai, Y. Murakami, S. Kishioka, A. Y. Nosaka, and Y. Nosaka, Electrochim. Acta, in press.

29) K. Sayama, A. Nomura, T. Arai, T. Sugita, and H. Sugihara, J. Phys. Chem. B., 110, 11352 (2006).

30) X. Cao, L. Cao, W. Yao, and W. Ye, Surf. Interfance. Anal., 24, 662 (1996).

31) M. Yagi, S. Maruyama, K. Sone, K. Nagai, and T. Norimatsu, J. Solid State Chem., 181, 175 (2008).

32) Y. Yang, Y. Murakami, A. Y. Nosaka, and Y. Nosaka, Adv. in Tech. Mat. Proc. J., 9, 115 (2007). 